\title{
The Economic Cost and Burden of Informal Caregiving for the Inpatient: The Case of Lemlem Karl Hospital, Maichew, Ethiopia
}

\author{
Habtamu Legese ${ }^{1}$, Ayenew Endalew ${ }^{2}$, Kidist Tibebu ${ }^{3}$, Desalew Mossie ${ }^{4}$ \\ ${ }^{1}$ Department of Economics, College of Business and Economics, Haramaya University, Dire Dawa, Ethiopia \\ ${ }^{2}$ Department of Economic, College of Business and Economics, Raya University, Maichew, Ethiopia \\ ${ }^{3}$ Department of Accounting \& Finance, College of Business and Economics, Raya University, Maichew, Ethiopia \\ ${ }^{4}$ Department of Chemistry, College of Natural and Computational Science, Raya University, Maichew, Ethiopia \\ Email address: \\ habtamulegese22@gmail.com (H. Legese)
}

\section{To cite this article:}

Habtamu Legese, Ayenew Endalew, Kidist Tibebu, Desalew Mossie. The Economic Cost and Burden of Informal Caregiving for the Inpatient: The Case of Lemlem Karl Hospital, Maichew, Ethiopia. International Journal of Economy, Energy and Environment. Vol. 5, No. 2, 2020, pp. 14-23. doi: 10.11648/j.ijeee.20200502.11

Received: November 29, 2019; Accepted: April 16, 2020; Published: April 29, 2020

\begin{abstract}
The objective of this study is to present new empirical findings about the economics of informally supplied health care with special emphasis on the labor market-related opportunity cost and to measure the burden of informal caregiving for the inpatient at Lemlem Karl hospital, Maichew, Ethiopia. The study employs ordinary list square and ordered logit method of regression. In addition, the study also employed measurement mechanisms like; opportunity cost, proxy good and Zarit Burden Scale. The mean time spent on informal caregiving was 73.18 hours/4.1days and the mean cost of informal caregiving for the inpatient at Lemlem Care Hospital by using the opportunity cost and proxy good valuation method is 689.56birr (23.74\$) and 724.653 birr (24.5\$) per 4.1 days respectively. The study also measures caregiver's burden level by using Zarit Burden Scale and the result depict that of the total respondents 51 (38.06\%) affected by moderate caregiving burden and followed by 41 $(30.60 \%)$ of the respondents with little caregiving burden. To reduce the cost and burden of principal informal caregivers and to fill this gap the following policy recommendations are made based on the findings of the study and the experience of the rest of the world. Enable informal caregivers to balance personal and social life with care responsibilities through respite care, develop and deploy a national caregiving strategy and the strategy should at a minimum include three policies; (a) Policy Related to Workplace Accommodation; (b) Financial Assistance policy; (c) Investment in informal caregiving research and development related projects.
\end{abstract}

Keywords: Economic Cost, Informal Care, Burden, Opportunity Cost, Inpatient, Proxy Good and Ethiopia

\section{Introduction}

Caregivers can be formal and informal. Formal caregivers are health-care professionals (HCPs) including nurses, personal support workers, rehabilitation specialists, and physicians who, are paid for the care and support they provide to the patients or clients. Informal caregivers are relatives, friends, or neighbors who provide unpaid practical support for those in need of assistance [1]. Unlike professional, informal caregivers, typically family members or friends, provide care to individuals with a variety of conditions including advanced age, dementia, and cancer. This experience is commonly perceived as a chronic stressor, and caregivers often experience negative psychological, behavioral, and physiological effects on their daily lives and health [2].

Caregiving is a complex and multidimensional activity, the nature and determinants of which evolve over time [3]. Different researchers and institutions define the term informal care and the people who provide informal care for those in need of assistance differently. [4] defines caregiving as "the provision of personal services to meet the physical and mental needs that allow a person to function at a socially 
determined acceptable level of capability, comfort, and safety." [5] "Informal caregivers are peoples who provide unpaid or arranges for paid help to a relative or friend because they have an illness or disability that leaves them unable to do some things for themselves or because they are getting older or sicker". [6] "Informal caregiving simply refers to activities and experiences involved in providing help and assistance to relatives or friends who are unable to provide for themselves. Whereas caring is the affective component of one's commitment to the welfare of another, caregiving is the behavioral expression of this commitment. Giving care to someone is an extension of caring about that person [7] "On the bases of heterogeneity informal care is defined as a nonmarket composite commodity consisting of heterogeneous parts produced (paid or unpaid) by one or more members of the social environment of the care recipient as a result of the care demands of the care recipient". In short, Caregivers provide the link between family life and community engagement for their care recipients, enabling them to integrate into society and function to the highest degree possible [8].

Regards caregiving burden, it is the collective set of stressful exposures or "stressors" that caregivers face. Burden also incorporates the physical, cognitive, affective, and economic load that caregivers bear. It can be considered as dynamic, a process that changes over time as the caregiver and the care recipient's circumstances change. It is measured by assessing the different objective and subjective stressors that caregivers often experience. The objective burden includes the number of hours in a given period spent on caregiving and the tasks for which the care recipient needs support. Whereas subjective burden includes the perceived demands that caregivers experience, including their emotional reactions to providing care, such as anger and embarrassment, feelings of entrapment, and a lack of control over one's life, time for leisure and socialization, and privacy [8].

Unpaid caregiving performed by family members for dependents is often overlooked in research and policies on development processes and outcomes [8]. Compared with non-caregivers, caregivers often experience psychological, behavioral, and physiological effects that are associated with impaired immune system function, coronary heart disease, and early death $[2,8]$ Argued that caregiving not only erodes the health and economic stability of individual caregivers, but that poor health and financial vulnerability caused by caregiving can, in turn, also lead to greater needs for caregiving, potentially creating a cyclical pattern of poverty.

Even if many community-based health care programs are based on the use of so-called informal or voluntary care as the major aspect of the program's feasibility, relatively little is known about the time spent on caregiving, its cost and the burden experienced by these informal caregivers [9, 7]. Given the lack of market for informal care inherently or since it is a less visible part of total care in terms of costs and effects and difficulties with the measurement of time spent on caring, the value of such an activity is challenging $[10,7]$.
Informal caregivers have an important, yet ambiguous, role in economic evaluation but minimizing the negative economic and health consequences of caregiving for caregivers requires a multidisciplinary approach that integrates the tools of both economics and health sciences to conduct research that informs the development, implementation, and evaluation of appropriate and effective social policy [8].

The general objective of this study is to present new empirical findings of the economics of informally supplied health care with special emphasis on the labor market-related opportunity cost and to measure the burden of informal caregiving for the inpatient at Lemlem Karl hospital, Maichew, Ethiopia. Having the above general objective; this research has also the following specific objectives like: to measure the cost and burden of informal caregiving, to analyze the impact of gender on the cost and burden of informal caregiving, to investigate the impact of socioeconomic status on the cost and burden of informal caregiving and to investigate the relationship between the cost and burden of informal caregiving.

Information about the cost and burden of informal caregiving is important because strategies directed at caregivers are likely to be more successful if they target modifiable determinants of the caregiving burden and address specific caregiver needs. Knowledge of these determinants would also help to identify caregivers most at risk of poor outcomes and deliver specific interventions at the appropriate time [3].

Research which focuses on informal caregiver's opportunity cost and the burden is useful for health, social and labor policy of the given country under study. It is important for the health policy because a decline in the supply of informal care would increase the demand for alternatives that are costlier (require a huge expenditure) from a health care budget perspective. It is important for social policy because knowledge of the determinants of the supply of informal care is crucial for the development of effective social policy programs [7]. It is also important for labor policy because such research will have a positive effect on the development of incentives for informal caregivers such as care leave facilities. Thus, the immediate outcome of this study provides pertinent result and policy implication to policymakers. Besides, we believe that the study will add something to the existing stock of knowledge and provoke or initiate for further study in the area as it reveals the difficulty in resolving the empirical question about the cost of informal caregivers for the inpatient.

\section{Materials and Methods}

The type of data employed in this research is crosssectional data and all the respondents are principal informal caregivers i.e. they are likely to provide most hours of informal care and to coordinate the care provided by other informal caregivers [7].

Specification of the Model and Description of the 
Variables.

Care recipient, caregiver, and household characteristics may determine caregiver outcomes [8]. The level of care required by the care recipient is a major factor that influences the caregiver's life and health effect [2]. In short, Factors associated with caregiver outcomes can be divided into three categories: 1) characteristics of the caregiver, 2) characteristics of the patient, and 3) characteristics of the care situation [11].

Background characteristics of the caregiver that may influence caregiver outcomes include age, gender, living situation, socioeconomic status, and type and quality of the relationship between the care recipient and caregiver. Patient characteristics that have been cited in the literature as having an influence on caregiver outcomes include disease-related and treatment-related characteristics, dependency, and physical and psychologic symptoms. Care characteristics may include duration of care, intensity of care, and different types of care. The more confining the care tasks are (i.e., the less time-flexible and the more disruptive they are to the caregiver's schedule), the more likely they are to create negative consequences. Moreover, because providing care requires time, the time available for other activities such as household chores, leisure, and visiting family and friends may be expected to decrease [11].

\subsection{Specification of the Model}

Model one (opportunity cost valuation method) through OLS.

$$
\begin{gathered}
\text { VICi }=\beta 0+\beta 1 i A P C+\beta 2 i E X P+\beta 3 i I C G H P D+\beta 4 i L S+\beta 5 i N E C+\beta 6 i H H S+\beta 7 i D S E X+\beta 8 i D M S \\
+\beta 9 i D \text { outofmaichew }+\beta 1 i D U R+\beta 11 i D E D U+\beta 12 i D S C R++\beta 13 i D \text { disable }+U i
\end{gathered}
$$

In this model, we calculate the value of informal care (VIC) by using the opportunity cost valuation method.

Model Two (proxy good valuation method)

$$
\mathrm{VIC}_{\mathrm{i}}=\text { Value of informal care } \mathrm{VIC} i=\beta i W i
$$

Model two proxy good valuation Method.

In this model, we calculate the value of informal care (VIC) by using the proxy good valuation method.

Model Three (through Ordinal logistic regression)

The ordinal logistic regression model can be expressed as a latent variable model [12]. Assuming a latent variable model exists, $y i *=x \beta+\varepsilon$, can be defined where $\mathrm{x}$ is a row vector $\left(1^{*} \mathrm{k}\right)$ containing no constant, $\beta$ is a column vector $\left(\mathrm{k}^{*} 1\right)$ of structural coefficients, and $\varepsilon$ is random error with standard normal distribution: $\varepsilon \sim \mathrm{N}(0,1)$.

$$
\begin{aligned}
& y i *=x \beta+\varepsilon i, \varepsilon \sim N(0,1) \\
I C G B i=\beta_{0} & +\beta_{1 \mathrm{i}} I C G H P D+\beta_{2 i} L S+\beta_{3 i} N E C \\
& +\beta 4 i \text { APC }+\beta_{5 i} D S E X+\beta_{6 i} D \text { Area } \\
& +\beta_{7 i} D \text { employment } \\
& +\beta_{8 i} D \text { Satisfaction }+\beta_{9 i} D \text { Ability } \\
& + \text { Ui }
\end{aligned}
$$

\subsection{Description of the Variable}

Name

$\mathrm{VIC}_{\mathrm{i}}$

APC

EXP

ICGHPD

$L S$

NEC

HHS

DSEX

DMS

D out of maichew
Description of the variable

is the value of informal care of the principal informal caregiver i per 4.1 days, because the average length of stay at Lemlem Karl Hospital is 4.1 days. The VIC will be calculated by using the two revealed preference valuation methods (opportunity cost and proxy good valuation method). VIC $=$ $\beta_{i} W_{\mathrm{I}}$ Where; $\beta_{\mathrm{i}}$ is the number of hours spent on informal caregiving task by the principal caregivers $\mathrm{i}$ and $\mathrm{W}_{\mathrm{i}}$ is wage per hour of the given person or the proxy for wage.

is for the age of the principal care giver

is for the Job experience of principal caregiver

Average Informal caregiving hours per day

Length of stay in the hospital with the inpatient

is number of external caregivers

stands for the household size of the inpatient

is dummy variable which stands for the gender of principal caregivers

$D f=1$ if the principal caregiver is female

$D f=0$ otherwise (if the principal caregiver is male)

is categorical variable which stands for the marital status of principal informal caregivers

D single stands for single informal care giver

$D$ divorced stands for divorced informal care giver

-widowed stands for widowed informal care giver

is dummy variable which stands for principal caregivers who are from out of maichew town

$D$ out of maichew $=1$ if they are not from maichew

$D$ out of maichew $=0$ otherwise 


\begin{tabular}{|c|c|}
\hline \multirow[t]{5}{*}{$D U R$} & $D U R=1$ if the principal informal caregiver is from urban area \\
\hline & $D U R=0$ otherwise (if the principal informal caregiver is from rural area) \\
\hline & stands for the educational level of principal caregivers (categorical variable) \\
\hline & $D$ illiterates dummy variable, which stands for illiterate principal informal caregivers \\
\hline & D primary is dummy variable for principal informal caregivers with primary education level \\
\hline \multirow[t]{4}{*}{$D E D U$} & $D$ Secondary is dummy variable for principal informal caregivers with secondary education level \\
\hline & $D C$ erteficate dummy variable for certificate/diploma holder principal informal caregivers \\
\hline & $\begin{array}{l}D \text { Degree is base group, which stands for Degree and above Degree holder principal informal } \\
\text { caregivers }\end{array}$ \\
\hline & is dummy variable which stands for the sex of informal care recipient \\
\hline \multirow[t]{3}{*}{ DSCR } & $D f c r=1$ if the informal care recipient is female \\
\hline & $D f c r=0$ otherwise (if the informal care recipient is female) \\
\hline & is dummy variable, which stands to indicate the informal care recipient ability \\
\hline \multirow[t]{3}{*}{$D$ Ability } & $\mathrm{D}$ disable $=1$ if the informal care recipient is not able move (walk) \\
\hline & $\mathrm{D}$ disable $=0$ otherwise \\
\hline & dummy, which stands for informal caregiver's area \\
\hline \multirow[t]{3}{*}{ D Area } & D rural $=1$ if the informal care giver is from rural area of southern Tigray \\
\hline & $\mathrm{D}$ rural $=0$ otherwise \\
\hline & dummy, which stands for the employment status of the principal informal caregivers \\
\hline \multirow[t]{3}{*}{ D employment } & D employed $=1$ if the respondent is employed \\
\hline & D employed $=0$ if not (unemployed) \\
\hline & $\begin{array}{l}\text { dummy, which stands for respondent's satisfaction by the service of Lemlem Karl hospital for principal } \\
\text { informal caregivers }\end{array}$ \\
\hline \multirow{2}{*}{ D satisfaction } & D satisfied $=1$ if the respondent is satisfied by th the service of the hospital \\
\hline & D satisfied $=0$ otherwise \\
\hline
\end{tabular}

\section{Data Presentation and Analysis}

\subsection{Descriptive Statistics}

Using survey method one hundred thirty-four (134) informal caregivers and informal care recipient were studied about their personal socioeconomic background. Out of the total respondents (principal informal caregivers) 41 (30.60\%) are from the rural area while $93(69.40 \%)$ are from the urban areas of the study area. Of the total respondents $80(59.7 \%)$ are female, the rest $54(40.3 \%)$ are male. The survey result depicts that $71(52.98 \%)$ of the respondents are between the age of 31 to 45 years. The remaining $45(33.58 \%)$ and 18 $(13.42 \%)$ of the respondents fallen below 30 years and above 45 years respectively.

With regards to the educational level of principal informal caregivers, the majority $64(47.7 \%)$ of the respondents are illiterate while $13(9.7 \%), 16(11.9 \%)$ of the respondents attended primary and secondary school education respectively. The remaining respondents 19 (14.7\%) and 22 $(16.4 \%)$ attended certificate and degree/above degree educational level respectively. On the other hand, the data shows that the majority, which is $97(72.38 \%)$, are married followed by single principal informal caregivers 29 (21.64\%) and the remaining $5(3.73 \%)$ and $3(2.23 \%)$ respondents are divorced and widowed respectively.

When we see the health status of informal care recipient, $32.83 \%$ of respondents are with slight health problem, $23.88 \%$ have moderate health problem, $39.55 \%$ of respondents have sever health problem and the rest 3.73\% are with extreme health problem. Concerning the movement ability of informal care recipient, the majority which is 74 $(55.22 \%)$ of them are movable and the rest $60(44.77 \%)$ are disable.

The study also measures caregiver's burden level by using Zarit Burden Scale and the result depict that of the total respondents the majority which is $51(38.06 \%)$ affected by moderate caregiving burden and followed by 41 (30.60\%) of the respondents with little caregiving burden. The remaining $30(22.39 \%)$ and $12(8.96 \%)$ of the respondents are affected by sever and mild informal caregiving burden respectively.

The mean time spent on informal caregiving was 73.18 hours/4.1days and the mean cost of informal caregiving for the inpatient at Lemlem Care Hospital by using the opportunity cost and proxy good valuation method is 689.56birr (23.74\$) and 724.653 birr (24.5\$) per 4.1 days respectively. From gender perspective the mean cost of informal caregiving by female respondent is 605.9 (20.89\$) and $760.13(26.17 \$)$ as calculated with opportunity cost and proxy good valuation method. Whereas the mean value of informal caregiving by male respondents is 685.33 (23.59\$) and $567.06(19.52 \$)$ as calculated with opportunity cost and proxy good valuation method.

\subsection{Econometric Result and Interpretation}

\subsubsection{OLS Regression Result Interpretation}

Out of the total independent variables age (APC), length of stay (LS), number of external caregivers (NEC), household size (HHS), marital status, area dummy (D rural) of the 
respondent are not significant. However, the remaining variables like paid job experience, informal caregiving hours per day, gender dummy (Df), area dummy (informal caregiver from Maichew), educational level of the respondent and movement ability of the informal care recipient significantly affect the cost (Value) of informal caregiving for the inpatient.

The dummy for sex of the informal caregivers is found negative and significant at $5 \%$. That is, other things remain constant; if the informal caregiver is female respondent then her cost of informal care will be lower from that of male respondents by $23 \%$.

Table 1. OLS regression result.



$*, * *, * * *$ indicates statistical significance at $1 \%, 5 \%$ and $10 \%$ respectively.

This means, the cost of informal caregiving of male respondent is higher than female respondent does. Other things remain constant as the paid job experience of the respondent increase by one year on average his/her informal caregiving cost will increase by $7.81 \%$. Concerning informal caregiving hour, the variable (ICGHPD) is significant at $1 \%$ and as the daily informal caregiving hour increase by on hour, on average the value of informal care will increase by 9.55\%.

As it is presented in the description of the study area parts Lemlem Karl Hospital, provide its service for both the Maichew and the surrounding southern Tigray catchment area population. This study found that the area of principal informal caregiver is statistically significant at $10 \%$. Other things remain constant if the principal informal caregiver is from Maichew city his/her value of informal will be higher than from that of principal caregivers from the surrounding southern Tigray by $27.61 \%$.

When we see the impact of educational level on informal caregiving cost, it is statistically significant at $1 \%$. Within the educational level, we have five categories, which include illiterate, primary educational level, secondary educational level, certificate/diploma level and principal informal caregivers with a degree and above degree educational level. In the above OLS regression degree and above degree holder principal informal caregivers are considered as the base group and all other principal caregivers with the remaining educational level are compared with them. The above OLS regression result depict that if the principal informal caregiver is illiterate then his/her value of informal care will be lower than with that of the degree holder principal caregiver by $79 \%$, if the principal informal caregiver is with primary educational level then his/her cost of informal care per 4.1 days will be lower than with that of the degree holder principal caregiver by $104.2 \%$, if the principal informal caregiver is with secondary educational level then his/her value of informal care will be lower from degree and above degree holder principal informal caregiver by $71 \%$ and if the principal informal caregiver is with certificate/diploma level then his/her value of informal care will be lower from degree and above holder principal informal caregiver by $47 \%$.

Concerning the relationship between the movement ability of informal care recipient and the cost of informal care incurred by principal informal caregivers it is statistically significant at $10 \%$. Other things remain constant principal informal caregivers who provide informal care for disable inpatient will incur $14 \%$ higher informal care giving cost compared to informal caregivers who provide informal care for inpatients with movement ability. 


\subsubsection{Estimation of Order Logit Regression Model and Analysis}

In this part of the study would gave a great emphasis for informal caregiving burden level through our order logit regression models with statistically significant variables and interpreting them by taking their simple logit coefficient initially and then odds ratio and marginal effects of the outcomes categorical variables respectively.

Table 2. Ordered logistic regression.

\begin{tabular}{|c|c|c|c|c|c|c|}
\hline & \multicolumn{6}{|c|}{ Number of obs $=134$} \\
\hline & \multicolumn{6}{|c|}{ LR chi2 $(9)=48.99$} \\
\hline & \multicolumn{6}{|c|}{ Prob $>$ chi $2=0.0000$} \\
\hline \multicolumn{3}{|c|}{ Log likelihood=-147.18315 } & \multicolumn{4}{|c|}{ Pseudo R2=0.1427 } \\
\hline ICGBL & Coef. & Std. Err. & $\mathbf{z}$ & $\mathbf{P}>\mathbf{Z}$ & [95\% Conf. & Interval] \\
\hline ICGHPD & .0243325 & .0200754 & 1.21 & 0.225 & -.0150144 & .0636795 \\
\hline LS & -.0413076 & .0285777 & -1.45 & 0.148 & -.097319 & .0147038 \\
\hline NEC & .0997862 & .1557533 & 0.64 & 0.522 & -.2054846 & .4050571 \\
\hline APC & $-.104395^{*}$ & .0210805 & -4.95 & 0.000 & -.1457121 & .0630779 \\
\hline Df & .1644412 & .364629 & 0.45 & 0.652 & -.5502185 & .8791008 \\
\hline D rural & $.7649112 * * *$ & .4019318 & 1.90 & 0.057 & -.0228606 & 1.552683 \\
\hline D employed & $1.386791^{*}$ & .4251019 & 3.26 & 0.001 & .5536063 & 2.219975 \\
\hline D satisfied & $-.8316471 * *$ & .3615734 & -2.30 & 0.021 & -1.540318 & -.1229762 \\
\hline D disable & .4313643 & .3572704 & 1.21 & 0.227 & -.2688728 & 1.131601 \\
\hline /cut1 & -3.25593 & .8388596 & & & -4.900064 & -1.611795 \\
\hline /cut2 & -2.747142 & .8267062 & & & -4.367457 & -1.126828 \\
\hline /cut3 & -.5812665 & .7900235 & & & -2.129684 & .967151 \\
\hline
\end{tabular}

In the above ordered logistic regression, we first see the iteration $\log$. At iteration 0, Stata fits a null model, i.e the intercept -only model. It then moves on to fit the full model and stope the iteration process once the difference in $\log$ likelihood between successive iteration becomes sufficiently small. The final log likelihood (-147.18315) is displayed again. Also at the top of the output, we see that all 134 observations in our data set were used in the analysis. The likelihood ratio chi-square of 48.99 with a p-value of 0.0000 tells us that our model as a whole is statistically significant, as compared to the null model with no predictors. The pseudo R-squared of 0.1427 is also given.

Out of the total independent variables, age of principal informal caregivers (APC), dummy, which stands for respondents from rural area (Drural), dummy, which stands for employed respondents (Demployed) and dummy, which stands for respondents who are satisfied by the service of Lemlem Karl hospital for principal informal caregivers (Dsatisfied) are statistically significant at 1\%,10\%,1\% and
$5 \%$ respectively.

For age of principal informal caregivers (APC), we would say that for a one-year increase in age, we expect.104395 decrease in the log odds of being in higher level of informal caregiving burden, given all of the other variables in the model are held constant. If the respondent is from rural area (Drural), we expect.7649112 increase in log odds of being in higher level of informal caregiving burden compered to informal caregivers from urban parts of southern Tigray. If the respondent is employed (Demployed), we expect 1.386791 increase in $\log$ odds of being in higher level of informal caregiving burden compered to unemployed respondents. If the respondent is satisfied by the service of Lemlem Karl Hospital for principal informal caregivers (Dsatisfide), the regression result depicts.8316471 decrease in log odds of being in higher level of informal caregiving burden compered to unsatisfied respondents.

Table 3. Ordered logistic regression (odds rati).

\begin{tabular}{|c|c|c|c|c|c|c|}
\hline \multicolumn{3}{|c|}{ Ordered logistic regression } & \multicolumn{4}{|c|}{ Number of obs $=134$} \\
\hline & & & \multicolumn{4}{|c|}{ LR chi2 $(9)=48.99$} \\
\hline & & & \multicolumn{4}{|c|}{ Prob $>$ chi $2=0.0000$} \\
\hline \multicolumn{3}{|c|}{ Log likelihood=-147.18315 } & \multicolumn{4}{|c|}{ Pseudo R2=0.1427 } \\
\hline ICGBL & Odds Ratio & Std. Err. & $\mathbf{z}$ & $\mathbf{P}>\mathbf{Z}$ & {$[95 \% \mathrm{Co}$} & val] \\
\hline ICGHPD & 1.024631 & .0205698 & 1.21 & 0.225 & .9850977 & 1.065751 \\
\hline LS & .9595339 & .0274213 & -1.45 & 0.148 & .9072666 & 1.014812 \\
\hline NEC & 1.104935 & .1720972 & 0.64 & 0.522 & .8142526 & 1.499388 \\
\hline APC & .9008694 & .0189908 & -4.95 & 0.000 & .8644066 & .9388703 \\
\hline Df & 1.178734 & .4298006 & 0.45 & 0.652 & .5768238 & 2.408733 \\
\hline D rural & 2.148804 & .8636725 & 1.90 & 0.057 & .9773988 & 4.724128 \\
\hline D employed & 4.001986 & 1.701252 & 3.26 & 0.001 & 1.739515 & 9.207103 \\
\hline D satisfied & .4353316 & .1574044 & -2.30 & 0.021 & .2143129 & .8842847 \\
\hline
\end{tabular}




\begin{tabular}{|c|c|c|c|c|c|c|}
\hline \multicolumn{3}{|c|}{ Ordered logistic regression } & \multicolumn{4}{|c|}{ Number of obs $=134$} \\
\hline & & & \multicolumn{4}{|c|}{ LR chi2 $(9)=48.99$} \\
\hline & & & \multicolumn{4}{|c|}{ Prob $>$ chi $2=0.0000$} \\
\hline \multicolumn{3}{|c|}{ Log likelihood=-147.18315 } & \multicolumn{4}{|c|}{ Pseudo R2=0.1427 } \\
\hline ICGBL & Odds Ratio & Std. Err. & $\mathbf{z}$ & $\mathbf{P}>\mathbf{z}$ & {$[95 \%$ Con } & val] \\
\hline D disable & 1.539356 & .5499663 & 1.21 & 0.227 & .7642405 & 3.100618 \\
\hline /cut1 & -3.25593 & .8388596 & & & -4.900064 & -1.611795 \\
\hline /cut2 & -2.747142 & .8267062 & & & -4.367457 & -1.126828 \\
\hline /cut3 & -.5812665 & .7900235 & & & -2.129684 & .967151 \\
\hline
\end{tabular}

In the output above the results are displayed as proportional odds ratios. For age of principal informal caregivers (APC), we would say that for a one-year increase in age, the odds of being in the sever level of informal caregiving burden versus the combined moderate, mild and little categories are 0.9008 grater, given that all of other variables in the model remain constant. Likewise, the odds of the combined mild moderate and sever burden level verses little burden level is 0.9008 times greater, given that all of the variables in the model are held constant. If the respondent is from rural area (Drural), the regression result depicts the odds of the sever burden level versus the little, mild and moderate burden level are 2.148804 times greater compered to informal caregivers from urban parts of southern Tigray, given that other variables in the model held constant. If the respondent is employed (Demployed), the regression result depicts the odds of the sever burden level versus the little, mild and moderate burden level are 4.001986 times greater compered to unemployed respondents, given that other variables in the model held constant. If the respondent is satisfied by the service of Lemlem Karl Hospital for principal informal caregivers (Dsatisfide), we expect that the odds of the sever burden level versus the little, mild and moderate burden level are.4353316times grater compered to unsatisfied respondents, given that other variables in the model held constant.

\subsubsection{Estimation of Marginal Effects After Order Logit Regressio}

Table 4. Marginal effects after ologit.

\begin{tabular}{llllllll}
\hline Variable & $\mathbf{d y} / \mathbf{d x}$ & Std. Err. & $\mathbf{z}$ & $\mathbf{P}>\mathbf{z}$ & {$[\mathbf{9 5 \%}$, C. I.] } & $\mathbf{X}$ \\
\hline ICGHPD & -.0047857 & .00395 & -1.21 & 0.226 & -.012529 & .002958 & 17.8507 \\
LS & .0081244 & .00576 & 1.41 & 0.158 & -.003158 & .019407 & 5.47015 \\
NEC & -.0196259 & .03061 & -0.64 & 0.521 & -.079622 & .04037 & 1 \\
APC & .0205324 & .00446 & 4.60 & 0.000 & .011791 & .029274 & 33.2313 \\
Df & -.0325728 & .07268 & -0.45 & 0.654 & -.175024 & .109878 & .597015 \\
D rural & -.1395398 & .06846 & -2.04 & 0.042 & -.273726 & -.005353 & .30597 \\
D employed & -.2744691 & .08443 & -3.25 & 0.001 & -.439947 & -.108992 & .537313 \\
D satisfied & .1662759 & .07287 & 2.28 & 0.023 & .023449 & .309102 & .440299 \\
D disable & -.0838442 & .06902 & -1.21 & 0.224 & -.219118 & .051429 & .447761 \\
\hline
\end{tabular}

$\left.{ }^{*}\right) \mathrm{dy} / \mathrm{dx}$ is for discrete change of dummy variable from 0 to 1 .

$\mathrm{y}=\operatorname{Pr}(\mathrm{ICGBL}==1)($ predict, outcome $(1))=.26908768$.

Table 5. Marginal effects after ologit.

\begin{tabular}{|c|c|c|c|c|c|c|c|}
\hline Variabl & e dy/dx & Std. Err. & $\bar{z}$ & $\mathbf{P}>\mathbf{Z}$ & \multicolumn{2}{|c|}{$[95 \%$, C. I. $]$} & $\bar{X}$ \\
\hline ICGHPD & -.0009458 & .00085 & -1.11 & 0.268 & -.002619 & .000728 & 17.8507 \\
\hline LS & .0016056 & .00122 & 1.32 & 0.186 & -.000776 & .003987 & 5.47015 \\
\hline NEC & -.0038785 & .00624 & -0.62 & 0.534 & -.016113 & .008356 & 1 \\
\hline APC & .0040577 & .00166 & 2.45 & 0.014 & .000814 & .007302 & 33.2313 \\
\hline Df & -.0062892 & .01391 & -0.45 & 0.651 & -.033551 & .020972 & .597015 \\
\hline D rural & -.0319355 & .02 & -1.60 & 0.110 & -.07113 & .007259 & .30597 \\
\hline D employed & -.0450868 & .01932 & -2.33 & 0.020 & -.082958 & -.007215 & .537313 \\
\hline D disable & -.016885 & .01514 & -1.12 & 0.265 & -.046562 & 2792 & .447761 \\
\hline
\end{tabular}

$(*) \mathrm{dy} / \mathrm{dx}$ is for discrete change of dummy variable from 0 to 1 .

$\mathrm{y}=\operatorname{Pr}(\mathrm{ICGBL}==2)$ (predict, outcome $(2))=.11069549$.

Table 6. Marginal effects after ologit

\begin{tabular}{llllllll}
\hline Variable & $\mathbf{d y} / \mathbf{d x}$ & Std. Err. & $\mathbf{z}$ & $\mathbf{P}>\mathbf{z}$ & $\mathbf{[ 9 5 \%}, \mathbf{C}$. I.] & $\mathbf{X}$ \\
\hline ICGHPD & .0024993 & .0022 & 1.14 & 0.255 & -.001803 & .006802 & 17.8507 \\
LS & -.0042429 & .00338 & -1.26 & 0.209 & -.010867 & .002382 & 5.47015 \\
NEC & .0102494 & .01622 & 0.63 & 0.527 & -.021533 & .042032 & 1 \\
APC & -.0107228 & .00411 & -2.61 & 0.009 & -.01878 & -.002666 & 33.2313 \\
\hline
\end{tabular}




\begin{tabular}{lllllll}
\hline Variable & $\mathbf{d y} / \mathbf{d x}$ & Std. Err. & $\mathbf{z}$ & $\mathbf{P}>\mathbf{z}$ & [95\%, C. I.] & $\mathbf{X}$ \\
\hline ICGHPD & .0024993 & .0022 & 1.14 & 0.255 & -.001803 & 17.8507 \\
Df & .0172515 & .0393 & 0.44 & 0.661 & -.059765 & .006802 \\
D rural & .0590298 & .03125 & 1.89 & 0.059 & -.002217 & .094268 \\
D employed & .1388187 & .05551 & 2.50 & 0.012 & .03003 & .120277 \\
D satisfied & -.0882816 & .04592 & -1.92 & 0.055 & -.178291 & .247607 \\
D disable & .0424575 & .03655 & 1.16 & 0.245 & -.029184 & .001728 \\
\hline
\end{tabular}

(*) dy/dx is for discrete change of dummy variable from 0 to 1 .

$\mathrm{y}=\operatorname{Pr}(\mathrm{ICGBL}==3)$ (predict, outcome $(3))=.46251222$.

Table 7. Marginal effects after ologit.

\begin{tabular}{lllllll}
\hline Variable & $\mathbf{d y} / \mathbf{d x}$ & Std. Err. & $\mathbf{z}$ & $\mathbf{P}>\mathbf{z}$ & [95\% C. I.] & $\mathbf{X}$ \\
\hline ICGHPD & .0032322 & .00269 & 1.20 & 0.230 & -.002041 & .008505 \\
LS & -.005487 & .00373 & -1.47 & 0.141 & -.012797 & .001823 \\
NEC & .013255 & .02082 & 0.64 & 0.524 & -.027543 & .054053 \\
APC & -.0138672 & .003 & -4.63 & 0.000 & -.019739 & -.007996 \\
Df & .0216105 & .04748 & 0.46 & 0.649 & -.071453 & .114674 \\
D rural & .1124456 & .0655 & 1.72 & 0.086 & -.015925 & .240816 \\
D employed & .1807371 & .05681 & 3.18 & 0.001 & .069385 & .292089 \\
D satisfied & -.1074286 & .04675 & -2.30 & 0.022 & -.199053 & -.015804 \\
D disable & .0582717 & .04917 & 1.19 & 0.236 & -.038096 & .15464 \\
\hline
\end{tabular}

(*) dy/dx is for discrete change of dummy variable from 0 to 1 .

$\mathrm{y}=\operatorname{Pr}(\mathrm{ICGBL}==4)($ predict, outcome $(4))=.15770461$.

$$
\begin{aligned}
& \mathrm{y}=\operatorname{Pr}(\mathrm{ICGBL}==1)(\text { predict, outcome }(1))=.26908768 \\
& \mathrm{y}=\operatorname{Pr}(\mathrm{ICGBL}==2)(\text { predict, outcome }(2))=.11069549 \\
& \mathrm{y}=\operatorname{Pr}(\mathrm{ICGBL}==3)(\text { predict, outcome }(3))=.46251222 \\
& \mathrm{y}=\operatorname{Pr}(\mathrm{ICGBL}==4)(\text { predict}, \text { outcome }(4))=.15770461
\end{aligned}
$$

Notice also that summation of the probability of outcome category $[\operatorname{Pr} \quad(\mathrm{ICGBL}==1) \quad$ (Little informal caregiving burden $), \quad[\operatorname{Pr} \quad(\mathrm{ICGBL}==2)$ (Mild informal caregiving burden)), [Pr (ICGBL==3) (Moderate informal caregiving burden $), \quad[\operatorname{Pr} \quad(\mathrm{ICGBL}==4)$ (Sever informal caregiving burden)) must equals to 1. (I. e..26908768 +.11069549 $+.46251222+.15770461=1)$.

A one year increase in the age of principal informal caregivers is associated with being 0.0205324 (2.053\%) more likely to be in little informal caregiving burden level, $0.0040577(0.405 \%)$ more likely to be in mild informal caregiving burden level, $-0.0107228(10.72 \%)$ less likely to be in moderate informal care giving burden level and $0.0138672(1.386 \%)$ less likely to be in sever informal caregiving burden level. Therefore, aggregate effects of high age lead to a lower impact on informal caregiving burden level.

As compared to urban informal caregivers, respondents from rural area of south Tigray.1395398 (13.95\%) less likely to be affected by little informal caregiving burden,.0319355 $(3.19 \%)$ less likely to be affected by mild informal caregiving burden,.0590298 (5.9\%) more likely to be affected by moderate informal care giving burden and.1124456 (11.24\%) more likely to be affected by severe informal caregiving burden. Therefore, this result depicts that if the respondent is from rural area his/her probability to be affected by higher level of informal caregiving burden will increase.

The result depicts that, employed principal informal caregivers are $0.2744691(27.44 \%)$ less likely to be in the little informal caregiving burden level, 0.0450868 (4.5\%) less likely to be in mild informal caregiving burden level,.1388187 (13.88\%) more likely to be affected by moderate informal caregiving burden level and 0.1807371 $(18.07 \%)$ more likely to be affected by sever informal caregiving burden level compared to unemployed principal informal caregivers.

Concerning satisfaction, if the respondent is satisfied by the service provided for principal informal caregivers by Lemlem Karl Hospital then they are 0.1662759 (16.62\%) more likely to be in little to no informal caregiving burden level, 0.0294343 (2.94\%) more likely to be in mild informal caregiving burden level, $0.0882816(8.82 \%)$ less likely to be in moderate informal caregiving burden level and.1074286 $(10.74 \%)$ less likely to be in sever informal caregiving burden level.

\section{Conclusion and Recommendation}

\subsection{Conclusion}

Informal caregiving is routine and ongoing. It arises out of a relationship with the informal care recipient in response to the demand for support which is greater than normally expected level due to their inability. Informal caregivers support with the tasks that recipients are unable to do for themselves. These may involve undertaking personal care household, financial and administrative tasks, helping with mobility, along with emotional support and companionship. Caregiving may also include some nursing activities. The caregiver role varies with the age and nature of the impairment of the care recipient (in our case the inpatient), but is likely to involve the caregivers taking responsibility to ensure the well-being of that person. This often includes ongoing monitoring, liaising with formal care systems, and 
attending to any shortfall not provided by paid health care workers from the health care institutions [13].

In most countries, informal care forms a major share of the healthcare and serve as a basis of many community-based healthcare services and is a major aspect of their feasibility it is not reflected in social statistics or little economic information exists about such care because informal care is a less visible part of care both in terms of costs and effects. Even though informal caregivers mostly serve without any payment, care provision can still come at a certain cost and burden. Moreover, it has often been ignored in economic evaluations and policymaking $[14,7]$

Using conservative assumptions, this paper suggests that the effort made by informal carers is considerable with grate value. In size, its value is comparable to, or exceeds, the value of care provided formally by the health care institutions. Beside the burdens of informal caregiving, the time spent on caring can reduce labor supply and, thus, can reduce output. Nonetheless, attempts to measure this cost are at a primitive stage specifically in Africa where Ethiopia belongs. Further research is needed [15].

\subsection{Recommendation}

Reducing the cost and burden of informal caregiving for the inpatients should be a critical agenda for the government as the increased cost and burden on caregivers is likely to lead to the costlier institutionalization of care recipients [16]. In the case of Ethiopia, there is no formal policy intended to support informal caregivers and to reduce the cost and burden of principal informal caregivers and to fill this gap the following policy recommendations are made based on the findings of the study and the experience of the rest of the world.

Enable informal caregivers to balance personal and social life with care responsibilities: To reduce the burden of principal caregivers we need to introduce a temporary institutional care for the inpatients, providing relief for their usual informal caregivers (respite care) and through this system there is a possibility to care for the caregivers. In short respite care services provide a break for caregivers.

Develop and deploy a national informal caregiving strategy: This strategy should explicitly and systematically focus on the reduction of the cost and burdens of principal informal caregivers or it should have details on how to exploit the nation's systems for health care, workplaces, and long-term services aspects of the informal caregivers and to support the principal informal caregivers health, values, and social and economic well-being, as well as to address the needs of the increasingly culturally and ethnically diverse caregiver population. Besides, the strategy should at a minimum include the following three policies:

A. Policy Related to Workplace Accommodation: Enable work-life balance for employed caregivers by flexible scheduling and this can be achieved through Leave for caregivers (short \& long term or paid \&unpaid care leave), Flexible work arrangements (providing careers sufficient income and a social network through work).

B. Financial Assistance policy: adopt federal policies that provide economic support for working and nonworking caregivers to offset the costs of caregiving, lost wages, and other related costs of the principal informal caregivers. This support may be given through caregiver's allowance (Payments to people from low-income groups who are looking for a person who needs support), cash for care benefit to inpatients (for those in-patients who do not have families) or through unemployment benefit for caregivers (If the principal informal caregiver decides to stop working to provide informal care). The cost of funding more services and supports for caregivers is minute compared to the value of their contributions.

C. Investment in informal caregiving research and development related projects.

\section{Competing Interests}

Authors have declared that no competing interests exist.

\section{Acknowledgements}

This study was supported in part by Raya University and we want to acknowledge that.

\section{References}

[1] Emofe Diameta (2018). The Burden Experience of Formal and Informal Caregivers of Older Adults with Hip Fracture in Nigeria. SAGE Open Nursing. Volume 4: 1-10. https://doi.org/10.1177/2377960818785155.

[2] Margaret Bevans, etal (2012). American Medical Association. All rights reserved. JAMA, January 25, 2012-Vol 307, No. 4. CME available online at www.jamaarchivescme.com and questions on $\mathrm{p}$ 415. CME available online at www.jamaarchivescme.com and questions on $\mathrm{p} 415$.

[3] Emily McCullaghetal, 2005. Determinants of Caregiving Burden and Quality of Life in caregivers of stroke patients. Journal of American Heart Association. https, Strok 2005; 36: 2181-2186, https://doi.org/10.1161/01.STR.0000181755.23914.53.

[4] Himmelweit, S. and Land, H. (2011) 'Reducing gender inequalities to create a sustainable care system. Kurswechsel, 4p. 49-63.

[5] Gould. D. (2004). Family caregivers and the healthcare system. The cultures of caregiving: conflict and. The John Hopkins University Press pp5-34.

[6] Leonard I. etal (1990). Caregiving and the Stress Process: An Overview of Concepts and Their Measures. The Gerontologist. New York University Pres70 Washington Square South New York, NY 10003.

[7] Bernard van den Berg; Werner B. F. Brouwer; Marc A. Koopmanschap. (2004). Economic Valuation of Informal Care: An Overview of Methods and Applications. The European Journal of Health Economics, Vol. 5, No. 1, 36-45. Stable URL: http://www.jstor.org/stable/3570100. 
[8] Friedemann \& Griffin (2013). Economic and Health Outcomes of Unpaid Caregiving: A Framework from the Health and Social Sciences. Minnesota population center. Working paper No. 2013-10.

[9] Ethel M Brinda et al. (2014). Cost and burden of informal caregiving of dependent older people in a rural Indian community. BMC Health Services Research 14: 207. http://www.biomedcentral.com/1472-6963/14/207.

[10] Alain \& Bérengère (2015). Economics of the Iceberg: Informal Care Provided to French Elderly with Dementia. VALUE IN HEALTH 18 (2015) 368 - $37 \begin{array}{lll} & 5 & 5\end{array}$ http://dx.doi.org/10.1016/j.jval.2015.01.002.

[11] Nijboer etal (1999). Determinants of Caregiving Experiences and Mental Health of Partners of Cancer Patients. American Cancer Society.

[12] William H. Greene (2003). Econometric analysis, Upper Saddle River, New Jeresy 07458.
[13] Godhead, A., \& McDonald, J. (2007). Informal Caregivers Literature Review: A report prepared for the National Health Committee. Victoria: Health Services Research Centre, Victoria University of Wellington.

[14] Bettio, F., \&Verashchagina, A. (2010). Long-Term Care for the elderly. Provisions and providers in 33 European countries. Luxembourg: Publications Office of the European Union.

[15] Bernard H. (2011). The Value and Costs of Informal care, paper submitted to the Commission on Funding of Care and Support.

[16] Kurasawa etal. (2012), "Factors Influencing Caregivers' Burden among Family Caregivers and Institutionalization of In-home Elderly People Cared for by Family Caregivers," Environmental Health and Preventive Medicine, 17 (6), pp. 474-483. https://doi.org/10.1007/s12199-012-0276-8. 